\title{
LA REAL EXPEDICIÓN FILANTRÓPICA DE LA VACUNA (1803 - 1810)
}

\author{
JORGE VEIGA DE CABO*, ELENA DE LA FUENTE DÍEZ**, \\ HELENA MARTÍN RODERO***
}

(*) Escuela Nacional de Medicina del Trabajo. Instituto de Salud Carlos III. Madrid

(**) Servicio de Obstetricia y Ginecología. Consorcio Hospital General Universitario. Valencia

(***) Biblioteca de la Facultad de Medicina. Universidad de Salamanca. Salamanca

AGRADECIMIENTOS:

Carmen Álvarez Roldán, por su inestimable ayuda en la elaboración de este artículo.

\section{RESUMEN}

La Expedición Filantrópica de la vacuna supuso una de las empresas sanitarias realizadas en el Siglo XVIII de mayor envergadura, por su complejidad, dificultad y sobre todo, por constituir una de las misiones de Salud Pública más importantes realizadas en la Historia. Supone el resultado de un proceso en el que una serie de acontecimientos históricos, sanitarios y sociales confluyen para generar uno de los primeros programas de intervención en salud pública a escala internacional y de expansión de la vacuna de la viruela. Se crean Centros de producción, almacenamiento y distribución de la vacuna, y programas de capacitación técnica enfocados a mantener campañas de vacunación poblacional.

\section{PALABRAS CLAVES}

Expedición Filantrópica, vacuna, viruela, variolización, Balmis, Salvany, programas de salud, salud pública, inclusas, orfanatos.

\begin{abstract}
One of the most important medical achievements made in the eighteenth century was the Philanthropic Expedition of the Vaccine. Due to its complexity and difficulty it was one of the most important Public Health undertakings in history. It was the outcome of a series of historical, social and health advances that converged in creating one of the earliest international programs for the expansion of the smallpox vaccine, creating centres for the production, storage and distribution of the vaccine together with technical training programs aimed at maintaining population vaccination campaigns.
\end{abstract}

\section{KEY WORDS}

Philanthropic Expedition of the Vaccine, Vaccine, Smallpox, Immunization, Balmis, Salvany, Health Programmes, Public Health, Orphanage, Foundling Hospitals. 
"No me imagino que en los anales de la historia haya un ejemplo de filantropía tan noble y tan extenso como este"

\section{Edward Jenner, 1806}

La Expedición Filantrópica de la Vacuna supuso una de las empresas sanitarias realizadas en el Siglo XVIII de mayor trascendencia, por su complejidad, dificultad y sobre todo, por constituir una de las misiones de Salud Pública más importantes realizadas en la Historia, lo que en cierta medida, contrasta con el escaso conocimiento que de ella se tiene a nivel general.

La Expedición supone el resultado de un proceso en el que se concatenan una serie de acontecimientos y circunstancias históricas, sanitarias y sociales que confluyen cronológicamente para constituirse como factor determinante en cuanto a concepción, diseño, articulación y gestión de uno de los acontecimientos sanitarios de mayor calado y dimensión internacional realizados durante el Siglo XVIII.

\section{EL PATRÓN DE LA VIRUELA Y LA LUCHA CONTRA ELLA EN LOS VIEJOS CONTINENTES.}

La lucha contra la viruela ha sido una constante de la humanidad a lo largo de los siglos. Al margen de las medidas sanitarias adoptadas en diferentes épocas de la historia, con mayor o menor eficacia, la batalla que realmente logra vencer a la enfermedad, podríamos decir que se ha librado en la lucha cuerpo a cuerpo. El verdadero éxito de la lucha contra ella se ha caracterizado por la efectividad de la inmunización individual, aunque por supuesto, establecida como una medida de carácter general.

De esta forma, y haciendo un breve repaso de los primeros datos que tenemos de la lucha contra la temible enfermedad, la primera técnica empleada fue la variolización, procedimiento que pretendía establecer un sistema de profilaxis en las personas sanas a partir del contacto con virus vivos procedentes de personas que padecían la enfermedad de forma leve.

Este sistema ya era utilizado en China y la India durante el Siglo XI e incluso antes. Diversas fuentes chinas atribuyen al médico Niu Jiuwu, en Jiangi, la utilización del mencionada técnica en el Siglo XVI, aunque la primera versión documentada corresponde a Zhang Lu en la obra Zhanghi yitong, manual de aplicación que relata tres métodos diferentes de variolización. El primero, consistía en introducir por las fosas nasales un algodón empapado en las pústulas de enfermos que habían padecido la enfermedad, manifestada de forma leve en cuanto a su grado de virulencia. El segundo, utilizaba polvo de costras desecadas que habían sido recogidas el año anterior, y que eran insufladas por las fosas nasales utilizando una caña de bambú. El tercero de los métodos se basaba en realizar cambio de ropas entre niños que padecían la enfermedad, también de forma leve, y niños sanos.

Estos métodos, fueron posteriormente perfeccionados por el médico de la Corte Imperial China Zhu Chungu, y fueron recogidos en un compendio médico que fue editado con la autorización de la Corte Imperial China en 1742, el "Yizong jiujian".

Estos conocimientos también eran conocidos en Asia Menor, Oriente Próximo, Cefalonia, Tasilea, el Bósforo y Constantinopla (1).

El momento clave de su expansión hacia Occidente fue cuando Lady Mary Wortley Montagen, esposa del embajador de Inglaterra en Constantinopla, que se encontraba impresionada por el empleo de los métodos variolizantes y sobre todo por sus resultados de efectividad en las poblaciones a las que se había aplicado, introduce la técnica de la variolización en su país de origen a su regreso a Inglaterra en 1717. Prueba de la confianza que Lady Mary Wortley tenía en el método de variolización era el hecho de que su hija fue una de las primeras en ser variolizadas y pronto, el procedimiento alcanzó tal popularidad y acogida que en 1722 los hijos de la familia real inglesa recibían también la variolización.

Pero, pese a los excelentes resultados obtenidos en la mayoría de los casos, la variolización no dejaba de ser un procedimiento no exento de riesgos. No olvidemos que se realizaba con virus vivos obtenidos del propio enfermo, aunque de una forma intuitiva, utilizando aquellos que potencialmente deberían ser menos virulentos, por proceder de las formas de enfermedad menos floridas o por "atenuar" su virulencia con el paso del tiempo desde la obtención del producto hasta su inoculación.

El verdadero paso de gigante en la lucha contra la enfermedad tuvo lugar el 14 de mayo de 1796, cuando Edward Jenner, observó que las personas que trabajaban en contacto con el ganado vacuno y que habían sido contagiadas de la "viruela vacuna", parecían mostrar una cierta resistencia a padecer la terrible viruela. Jenner decide realizar un estudio experimental que intentaba argumentar científica- 
mente la relación causa-efecto que había observado de forma empírica. Mediante dos incisiones superficiales, inoculó las secreciones extraídas de una pústula en la mano de la ordeñadora Sarah Nelmes, que había contraído la enfermedad directamente de su vaca, a un niño de 8 años, llamado James Phipps, quien posteriormente desarrolló un estado de inmunidad hacia la viruela. Este hecho le sirvió de base para establecer los pilares científicos del descubrimiento de la vacuna.

\section{LA APARICIÓN DE LA VIRUELA EN EL NUEVO CONTINENTE}

Aunque la viruela ha sido una de las epidemias más temibles de las muchas que azotaron a Europa y Asia a lo largo de los siglos, se admite que en América, la enfermedad fue desconocida hasta comienzos del Siglo XVI. El detonante para que la enfermedad se extendiese por todo el territorio del Nuevo Mundo tiene su origen en 1518 cuando Pánfilo de Narváez, lugarteniente de Diego de Velázquez, Gobernador General de Cuba, emprendió una persecución en busca de Hernán Cortés por tierras de México. Parece ser que uno de los esclavos provenientes de África, que componían la expedición de Narváez y que se encontraba afectado de la enfermedad, fue el causante de la propagación de ésta, convirtiéndose de esta forma en el foco involuntario de expansión de la viruela por los territorios de las antiguas Indias de América.

Según redacta Villalba "...el fatal esclavo que pasó esta enfermedad entre los habitantes de Zempoala, les dexó la mortal semilla para perpetua memoria de su infeliz arribo, de suerte que seiscientos mil indios fueron víctimas de este terrible contagio, porque ignorantes de su carácter venenoso se bañaban para limpiar las manchas que observaban en la piel y repercutiendo así el humor les mataba prontamente". (2)

Aunque ésta es la versión oficialmente aceptada desde que José Felipe Flores, natural de Guatemala y médico de cámara de Carlos IV, afirmase que "era una enfermedad exótica en aquellos países y enteramente desconocida de sus antepasados", no está del todo claro si la enfermedad pudo estar presente en el pasado; así, en el conjunto arqueológico de Tiahanaco, en Bolivia, en el Templo de las Cabezas, aparecen representaciones de diferentes enfermedades en rostros humanos, alguna con lesiones similares a granos y marcas en la cara, que se atribuyen a la viruela. Así mismo, en algunos códices mexicanos que representan rostros con lesiones, se puede advertir marcas que podrían parecerse a formas típicas de viruela (3).

\section{CIRCUNSTANCIAS SOCIO SANITARIAS PRECEDENTES A LA EXPEDICIÓN}

Desde que la monarquía borbónica se estableció en España en 1700, sufrió los azotes reiterados de la enfermedad, la cual llegó a castigar con la muerte a alguno de sus miembros. En 1789 nace la cuarta hija de Carlos IV y Maria Luisa de Parma, la infanta María Isabel, quien en 1798 contrae la fatal enfermedad. Aunque la infanta se cura, la viruela deja serias secuelas en su cara, lo que marca profundamente a Carlos IV y le lleva a plantearse seriamente el buscar medidas que permitan evitar el contagio al resto de la familia.

El año en que ocurre este suceso, 1798, coincide con la publicación del tratado de Edward Jenner "An inquiri into the causes and effects of the variolae vaccine, or Cow Pox" sobre el descubrimiento que él mismo había realizado unos años atrás, en 1796. Sin embargo, la vacuna de Jenner no entra en España hasta 1800, a iniciativa de Francesc Piguillem. Este retraso en relación a Inglaterra, donde recordemos se introdujo la técnica de la variolización en 1717, fue debido a que los propios médicos de Cámara con el apoyo del Protomedicato, se opusieron a la práctica antivariólica en nuestro país por el temor a los efectos negativos que podría tener su práctica generalizada. El Protomedicato llegó a prohibir en 1757 la publicación "memoria sobre la inoculación de la vacuna de la viruela" de Cristian de la Condamine, traducida al castellano por Rafael de Osorio.

Paralelamente a los criterios de los que defendían la oposición a la técnica antivariólica generalizada, convivían tendencias científicas contrapuestas, cuyos máximos exponentes fueron tres médicos que se habían desplazado a Londres para aprender la técnica con Sutton: el español Miguel Gernán y dos médicos irlandeses afincados en España, Bartolomé O'Sullivan y Timoteo O'Scanlan, este último, autor del "Ensayo Apologético de la Inoculación".

La fuerza que fueron adquiriendo las tendencias a favor de la técnica antivariólica, junto a la preocupación manifiesta de Carlos IV por prevenir de la viruela al resto de miembros de la familia, indujeron al primer médico de la Cámara del Rey, Francisco Martínez del Sobral, a proponer al Monarca la aplicación del método de la variolización a toda la familia real.

Aunque la medida entrañaba ciertos riesgos, el resultado fue extraordinariamente satisfactorio, produciendo tal efecto en el Monarca que el 30 de noviembre de 1798, emite una Real Cédula por la 
que se impone la práctica de la inoculación de las viruelas naturales a la población.

Este acontecimiento supone una medida sanitaria de primer orden sobre todo si tenemos en cuenta que se trata de una actuación adoptada por el Estado para protección de la población general frente a una enfermedad, pero además, podemos considerarlo como el preámbulo para la implantación de la vacuna con carácter general en la población española que se adoptaría unos años después y que supuso la antesala de la organización de la expedición que nos ocupa.

La vacuna descubierta por Jenner también se traslada desde Europa a algunos territorios de Ultramar, así, se introduce oficialmente en 1777 en Buenos Aires, en 1778 en Lima, en 1792 en Santa Fe de Bogotá y posteriormente en la Habana y la ciudad de México, aunque las inoculaciones que se realizan sobre la población, se centran en campañas de vacunación locales y en determinados territorios sin que se programe como una campaña para la difusión generalizada para toda, o la mayor parte de la población del Nuevo Mundo, como se plantea a través de la Real Expedición Filantrópica de la Vacuna.

\section{LOS PREÁMBULOS DE LA EXPEDICIÓN}

Unos años más tarde de que Carlos IV instaurase la inoculación de las viruelas naturales con carácter general en la población española, en 1802 se desencadena en Nueva Granada o Santa Fe, una epidemia de viruela que en pocos meses alcanza enormes dimensiones. Así, el 13 de marzo de 1803, el Consejo de Indias comienza a solicitar informes a la Corona Española sobre "...Si se creía posible extender la vacuna a los países de Ultramar y que medios serían más acertados para el intento...".

A partir de ese momento, y dentro de un clima favorable por las experiencias vividas en la propia familia real, así como por los excelentes resultados obtenidos cuando estas medidas se extendieron a la población general, se pone en marcha una ágil maquinaria encaminada a buscar soluciones que permitiesen controlar de forma generalizada las epidemias que se venían produciendo en diferentes territorios de Ultramar.

A los nueve días, el 22 de marzo, Francisco Requena, miembro del Consejo de Indias, informa favorablemente sobre la necesidad de la puesta en marcha de un plan de actuación y solicita un informe al médico de Cámara, José Felipe de Flores, en el que se establezcan las bases de la misma. El infor- me, que éste redacta de forma urgente, describe las recomendaciones más importantes a tener en cuenta para garantizar el éxito de la expedición, incluye su criterio sobre la facilidad que suponía difundir la vacuna en los territorios de Ultramar y la propuesta de derrotero general para la expedición filantrópica.

Comienza así el diseño de la operación, en el que se definen tanto las fases previas de la misma como los tres puntos esenciales que deberían ser contemplados para el éxito de la misión. En primer término, habría que establecer los mecanismos que permitieran alcanzar el objetivo principal, que no era otro que difundir la vacuna desde el Reino de España a todos los Virreinatos posibles de los territorios Ultramarinos. En segundo lugar, era necesario arbitrar procedimientos que permitieran instruir a los sanitarios locales de las poblaciones visitadas para que pudieran dar continuidad a la práctica de la vacunación a lo largo del tiempo. Por último, se tendrían que crear en los diferentes Virreinatos visitados, lo que se denominaron, Juntas de Vacunación, que actuarían como centros para conservar, producir y abastecer de las vacunas activas que permitieran mantener la campaña de una forma permanente.

El 28 de marzo el proyecto se encontraba ya concebido y contemplaba los programas de actuación sobre cada uno de los diferentes aspectos que habían sido cuidadosamente estudiados. El siguiente paso era definir los sistemas para la financiación de la Expedición. De esta forma, se estableció que los gastos de navegación del viaje que transportaría la vacuna desde España a las costas de Ultramar, serían soportados por la Real Hacienda. Esto suponía asumir los costes destinados, principalmente, a fletar el barco y a sufragar los honorarios de los expedicionarios. La estrategia de la financiación establecía que una vez que la vacuna alcanzase el territorio de las Américas, los gastos de las diferentes expediciones locales, orientadas a la distribución de las vacunas por los distintos territorios, la creación de las Juntas de Vacunación y los gastos de soporte del personal destinado a mantener las campañas de vacunación en las distintos zonas, deberían ser sufragados por los Tributos de Indios, Censos de Indios y los Diezmos Eclesiásticos, que eran los procedimientos habituales utilizados para mantener las arcas de la Hacienda Pública en los Virreinatos.

Resuelto el tema de la financiación, no menos importante era dotar a la Expedición del marco legal necesario para que se constituyese en calidad de Real Expedición y por tanto contase con el apoyo que requería para el alcance, difusión y éxito para el 
que había sido concebida. Así, el 5 de junio de ese mismo año, se promulga una Real Orden en la que se comunica la propagación de la vacuna contra la viruela a todos los territorios de Ultramar, y el 1 de septiembre se edita otra Real Orden que establece actuaciones concretas para cada uno de los territorios, implicando tanto a autoridades civiles como militares.

Por último, y una vez diseñado el proyecto en su conjunto, había que dar paso a la parte operativa, y en el orden práctico, poner en marcha la operación, para lo que era necesario dotarla de personal adecuado y de los recursos materiales necesarios.

En lo que respecta a la elección de los navíos, se primó la rapidez sobre la comodidad; así, desde el primer momento se optó por buques de correo de guerra que eran más ligeros y se encontraban habituados a mantener rutas frecuentes con América. En lo que respecta a los recursos humanos de la expedición, inicialmente, Francisco Requena, miembro del Consejo de Indias y promotor de la expedición, nombró dos directores, ambos médicos, Francisco Xavier Balmis y Berenguer y José Felipe Flores.

La razón para que la expedición contara con dos directores era que inicialmente había sido concebida para que partieran dos embarcaciones desde España con destinos diferentes al Nuevo Mundo. Por una parte, Francisco Xavier Balmis capitanearía la expedición que pondría rumbo a Veracruz, mientras José Felipe Flores, médico miembro de la Cámara del Rey y encargado de elaborar el informe inicial de la operación, se ocuparía de conducir la expedición que se dirigiría desde España directamente a Cartagena.

Aunque este era el plan que se barajaba en principio, diferentes motivos estratégicos, económicos, y finalmente por decisión del propio Monarca, se nombra Director exclusivo de la expedición a Francisco Xavier Balmis, quien sería el encargado de trasportar en un único viaje la vacuna a los Virreinatos de Ultramar, por lo que José Felipe Flores, queda excluido de la expedición.

El mismo Balmis, contando con la supervisión del Monarca, se encarga de confeccionar su propio equipo, para lo que estableció como premisa que los componentes del equipo debían conocer más las practicas sanitarias que ser poseedores de títulos. El equipo expedicionario de Balmis quedó formado, además de por él mismo como Director de la expedición, por tres facultativos ayudantes: José Salvany y Lleopart (que sería nombrado Subdirector durante la expedición), Manuel Julián Grajales y Antonio
Gutiérrez Robredo. Como practicantes: Francisco Pastor Balmis y Rafael Lorenzo Pérez y como enfermeros: Basilio Bolaños, Pedro Ortega y Antonio Pastor.

Pero además del equipo técnico, la expedición debía contar, inicialmente, con unos 15 ó 20 niños de edades comprendidas entre los ocho y diez años, que cumpliesen la condición de no haber pasado las viruelas y que serían vacunados en sucesivos pases de unos a otros a lo largo de la travesía, al objeto de transportar la vacuna de forma activa hasta su llegada a puerto de destino en las Américas. Por lógica, las familias normalmente estructuradas eran reticentes a prestar a sus hijos para una aventura de estas características y de riesgos inciertos, por lo que desde el principio se optó por recurrir a reclutar niños procedentes de Inclusas o familias desestructuradas. En compensación, el Erario Público se comprometía a hospedarlos y cuidarlos, formándoles en una profesión que les garantizase y permitiera integrarse laboralmente en la sociedad. Literalmente como figura en la Circular para la propagación de la vacuna, fechada en San Ildefonso el 1 de septiembre de 1803: "...serán bien tratados, mantenidos y educados, hasta que tengan ocupación o destino con que vivir, conforme a su clase y devueltos a los pueblos de su naturaleza, los que se hubiesen sacado con esa condición".

Esta táctica operativa obligaba a introducir en el equipo a un nuevo componente, una persona que cumpliese con las características y conocimientos necesarios para poder atender y cuidar a los niños a lo largo de la travesía. Balmis nombra a la Rectora de la Casa de Expósitos de la Coruña, Isabel Sendales y Gómez, como la persona que se encargaría de cuidar a los niños a lo largo de toda la expedición, no sólo de los niños que partían desde España, sino de los que fuese necesario incorporar a la expedición a lo largo de su recorrido para transportar la vacuna de unos territorios a otros a través del Nuevo Continente.

\section{LA EXPEDICIÓN, RUMBO A AMÉRICA}

El 30 de noviembre de 1803, la expedición, compuesta por Balmis, su equipo técnico, los niños, la cuidadora de éstos y la tripulación, parte del puerto de la Coruña a bordo de la corbeta "María Pita", dirección a Santa Cruz de Tenerife, donde después de atracar en el puerto tinerfeño, permanece durante un mes para cumplir la primera de sus misiones antes de atravesar el Atlántico, vacunar a la población y establecer en Santa Cruz de Tenerife un centro de vacunación que permita difundir y mantener 
la campaña de vacunación en las demás islas que componen el archipiélago.

Completada esta misión, la corbeta María Pita pone rumbo hacia Puerto Rico, donde atraca casi un mes más tarde sin que durante la travesía tuviesen incidentes de interés, pero a su llegada a Puerto Rico, las cosas no fueron tan alentadoras como en principio cabría esperar. El primer problema con el que se enfrentaron a su llegada fue que, pese a toda la estrategia de apoyo legal con la que contaba la expedición, las autoridades locales de Puerto Rico se desentendieron desde el primer momento de la expedición, manifestando una ausencia absoluta de colaboración. Esta actitud era consecuencia de que la vacunación había sido ya instaurada en Puerto Rico por el Dr. Francisco Oller Ferrer, médico de la isla que la había importado desde la isla inglesa de Saint Thomas. El segundo problema con el que se encontraron era que, al haber sido instaurada la vacuna hacía un tiempo, no se encontraban niños que cumpliesen las característica inmunológicas necesarias para dar continuidad a los pases de la vacuna y poder seguir con la misión en otros territorios.

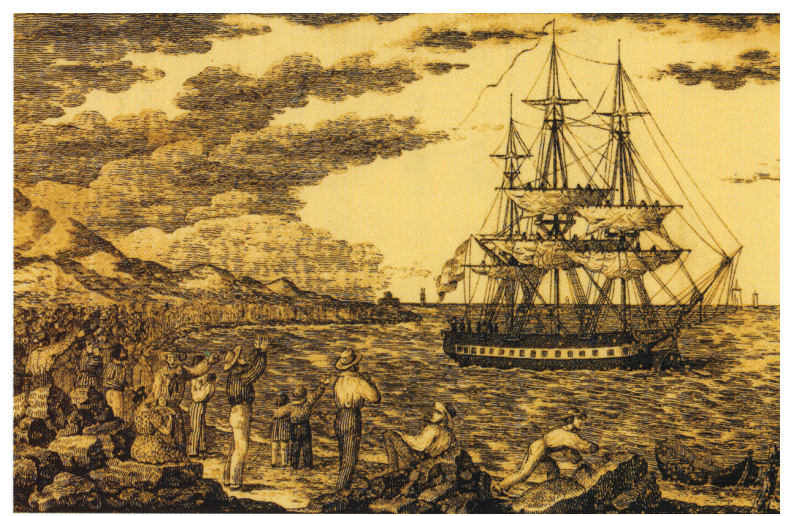

Corbeta "María Pita" partiendo de uno de los puertos del Caribe. 1803-1804. (Grabado de Francisco Pérez, Biblioteca Nacional).

Estas circunstancias fueron motivo de fuertes enfrentamientos entre Balmis, el facultativo de la isla y el Gobernador de la misma, Ramón de Castro. Esta situación llevó a Balmis a tomar la decisión de partir hacia su siguiente objetivo, la Capitanía General de Caracas, pero debido a que por una parte no conseguían niños al ritmo deseado, y que por otra, no había vientos favorables para la navegación, la corbeta no pudo poner rumbo al puerto de la Guayra para dirigirse a Caracas hasta el 3 de marzo, lo que incrementó los problemas y las tensiones ya existentes.
Esta situación se repetirá a lo largo de la expedición en varias ocasiones y se convierte en el principal problema para Balmis, llevándole a fuertes enfrentamientos con las autoridades locales de diferentes territorios y a protagonizar duras críticas hacia algunos de sus colegas que habían logrado implantar la vacunación con anterioridad a su llegada.

Cuando la expedición de Bamis finalmente logra zarpar de Puerto Rico rumbo a la Guayra se presenta una nueva dificultad, las pésimas condiciones de navegación por los mares del Caribe que convierten el viaje en un suplicio. Esto obliga a Balmis y a su equipo a atracar en la ciudad de Puerto Cabello el 20 de marzo, ciudad mucho más alejada de la Capitanía General de Caracas que el puerto de la Guayra, donde pretendían desembarcar, lo que retrasó aún más la fecha de llegada a su destino previsto.

Los inconvenientes con los que hasta el momento se había encontrado Balmis desde su primer desembarco en Puerto Rico, unido a la necesidad de alcanzar Caracas lo antes posible, le empujan a tomar la decisión de dividir la expedición en tres grupos, con la esperanza de que alguno de ellos logre alcanzar el objetivo en el menor tiempo posible. Un grupo continuaría su ruta por tierra, atravesando el Valle de Aragua. Otro grupo se dirigiría por mar a bordo del guardacostas Rambli y el tercero, a bordo de la corbeta María Pita, todos ellos con dirección a Caracas. Pero los planes de Balmis no alcanzan el efecto deseado y al final, los tres grupos invirtieron más de 10 días en alcanzar la capital venezolana.

Sin embargo, cuando pisan Caracas, el panorama es muy diferente al ambiente hostil con el que se habían encontrado a su llegada a Puerto Rico. Por el contrario y para su satisfacción, en Caracas son recibidos calurosamente. Allí crean la primera Junta de Vacuna de la expedición en el Nuevo Continente, desde la que se difundiría la vacuna para todo el territorio de Venezuela. Esto, además de levantar la moral del equipo, también sirvió para establecer un modelo que serviría de referencia a otras capitales de América.

\section{DIVISIÓN DE LA EXPEDICIÓN EN DOS GRUPOS}

Desde Caracas, el siguiente objetivo que debía alcanzar la expedición era el conocido Virreinato de Nueva Granada o de Santa Fe, lugar en el que se había iniciado la epidemia de viruela y que en su día hizo saltar la voz de alarma para que la corona 
española articulase la expedición filantrópica. Este objetivo, pieza original de la expedición sanitaria y que debía constituir uno de los destinos más satisfactorios para los expedicionarios, se convirtió en un segundo foco de resistencia hacia la expedición, por motivos similares a los que acontecieron en Puerto Rico.

Precisamente la situación de epidemia que había sufrido la zona desde 1802, había obligado al Virrey de Santa Fe a tomar medidas propias para luchar contra la enfermedad, por lo que nombró al médico Lorenzo Vergés como comisionado de urgencia para frenar la epidemia, y al igual que había ocurrido en Puerto Rico, el facultativo había instaurado la vacunación en el territorio. Debido a estas circunstancias, el propio Vergés era reacio a recibir a la expedición de Balmis, y Balmis criticó duramente los procedimientos científicos y la metodología que Vergés había empleado para realizar las vacunaciones, lo que generó nuevas tiranteces y obligó a Balmis a detener provisionalmente su marcha hacia Santa Fe.

Había otro dato de enorme interés, desconocido para Balmis, y es que las autoridades sanitarias de Santa Fe habían comisionado también a Vergés para extender la vacuna a otros territorios azotados por la enfermedad, y habían enviando a tres facultativos adiestrados en la vacunación a Nueva España, la Habana, el Perú y Buenos Aires, convirtiendo además la isla de Puerto Rico en el Centro Difusor de la vacuna. Este Centro actuaba como verdadera Junta de Vacunas y éste fue el motivo, que como sabemos, originó los primeros enfrentamientos de Balmis a su llegada a Puerto Rico.

El 9 de abril, Balmis recibe la noticia del fallecimiento de Vergés, con lo que se abre de nuevo la puerta para la continuidad a la misión. Como la expedición había sufrido ya varios retrasos, y la enfermedad seguía castigando otros territorios del Nuevo Mundo, no convenía demorar más la expedición y con ello, la difusión de la vacuna en aquellas poblaciones que aún la necesitaban.

Por segunda vez, Balmis opta por dividir la expedición, esta vez en dos grupos, al objeto de abarcar en el menor tiempo posible la mayor extensión de territorio. En esta ocasión, la división de la expedición sería definitiva y a partir de ese momento ambos grupos tomarían trayectorias diferentes. Así, el 8 de mayo de 1804, Francisco Xavier Balmis y Berenguer, Director de la expedición, optaría por dirigirse hacia el Virreinato de Nueva Granada para abarcar los territorios de América Septentrional. Nombra Subdirector de la expedición a José Salvany y Lleopart, a quien le conferiría el liderazgo del otro grupo, que quedaría formado por el facultativo Manuel Julián Grajales, el practicante Rafael Lozano y el enfermero Basilio Bolaños, y quienes pondrían rumbo a Santa $\mathrm{Fe}$ con la misión de extender la vacunación por los territorios de América Meridional.

\section{SEGUIMIENTO DEL GRUPO DE LA EXPEDICIÓN LIDERADO POR BALMIS}

El mismo 8 de mayo, fecha en la que Balmis toma la decisión de dividir la expedición, su grupo parte en la corbeta Maria Pita en dirección a Nueva España, fondeando en la Habana el 26 de mayo tras una accidentada travesía por el Caribe que afectó la salud de los niños. Al atracar en puerto cubano Balmis descubre que la vacuna había sido instaurada también en la isla con éxito por el médico Tomás Romay, razón por la que decide no perder tiempo y partir de inmediato hacia Nueva España. Para continuar la misión necesita al menos cuatro niños que pudieran transportar la vacuna hacia su nuevo destino. Solicita a las autoridades cubanas ayuda para que le faciliten los niños necesarios, pero su solicitud es desatendida pese a las reiteradas veces que la presenta formalmente.

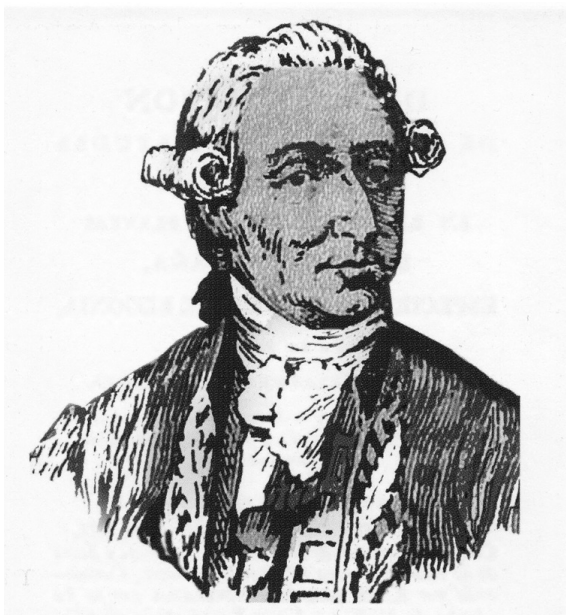

\section{Francisco Xavier de Balmis y Berenguer (Grabado de Elías Corona).}

Al cabo de tres semanas a la espera de contestación por parte de las autoridades cubanas, consigue, utilizando una vía alternativa, tres esclavas que podían transportar la vacuna de manera similar a como lo venían haciendo los niños, manteniendo así activa la vacuna hasta su nuevo destino. Solucionado su principal problema, comunica al Capitán General de la isla, el marqués de Someruelos, que ya no necesita que sean atendidas sus insistentes solici- 
tudes y el 18 de junio, la corbeta María Pita zarpa de la Habana poniendo rumbo a Sisal, en la península del Yucatán.

La navegación entre la Habana y Sisal presentó una vez más, las mismas dificultades que se habían encontrado hasta el momento en todas sus travesías por los mares del Caribe. Logran atracar en Sisal el 25 de junio. La expedición fue recibida por el Gobernador de Mérida, Benito Pérez, que se había tomado la molestia de desplazarse hasta Sisal para recibirles personalmente y darles la bienvenida.

El 29 de junio, días después de desembarcar en Sisal, llegan a Mérida, donde ese mismo día y sin tiempo que perder, comienzan las vacunaciones de la población con un fuerte apoyo por parte de las autoridades locales. Se establece otra Junta de Vacuna para difundir la vacunación a lo largo de Nueva España y los territorios limítrofes. Posteriormente emprenden camino hacia la Capitanía General de Guatemala, donde instaura la vacunación, al igual que en Oaxaca, trayecto escogido para su regreso a Sisal.

De nuevo en Sisal el grupo de Balmis pone rumbo hacia Veracruz el 19 de julio, arribando a puerto cinco días después, y donde un vez más, comprueba que la vacuna había sido instaurada también con éxito, lo que supone un nuevo contratiempo para el grupo de Balmis. Una vez más, su principal problema era lograr recabar el número adecuado de niños que reunieran las características necesarias para dar continuidad a los pases y por tanto a la expedición. En esta ocasión tuvo que recurrir a la tropa para solventar el problema y logró salir el 1 de agosto con dirección a México, donde llegó ocho días más tarde.

Balmis llega a la Capital de Nueva España (México) y protagoniza un nuevo enfrentamiento con las autoridades locales, en esta ocasión con el Virrey Iturriagaray, lo que complica de nuevo la misión y le obliga a desplazarse hacia las poblaciones del norte del territorio con el fin de establecer, lejos de la capital y lejos de las interferencias del Virrey, varias Juntas de Vacunaciones que pudieran difundir la vacunación a lo ancho de aquel territorio, aún estéril a la inmunización y vulnerable a la enfermedad, y con el fin de obtener niños con los que poder dar continuidad a la expedición.

Tras conseguir 26 niños mexicanos, el 7 de febrero de 1805 parte rumbo a Filipinas, recorriendo Manila, Cebú, Mizamiso, Mindanao y Zambuanga, en esta ocasión a bordo del buque Magallanes.
La navegación por el Pacífico participó de las mismas características y dificultades que las experiencias anteriores por el Mar del Caribe, pero por si esto no era suficiente, se encontró con un contratiempo sobreañadido; el grupo expedicionario de Balmis se vio obligado a tener que realizar este viaje en una línea marítima regular que hacía el trayecto de Acapulco a Manila, en el navío Santa Bárbara. Balmis se queja así de las malas condiciones en las que realizaron la travesía, especialmente los niños "...estuvieron mui mal colocados en un parage de la Santa Bárbara lleno de inmundicias y grandes ratas que los atemorizaban, tirados en el suelo rodando y golpeándose unos con otros a otros vaivenes...".

A partir de esta travesía, Balmis se sintió agravado de los problemas de una fuerte disentería que venía arrastrado desde hacía algún tiempo y de la que no había terminado de reponerse. Los fuertes trastornos intestinales de los que se encontraba aquejado impidieron que pudiera volver a Nueva España. Balmis conocedor de que la vacuna no se había distribuido aún en China, toma la decisión de dirigirse a Macao con intención de encontrar un clima más favorecedor para reponerse de sus males intestinales y aprovechar la ocasión para extender la misión de difusión de la vacuna.

Decide realizar el viaje a Macao acompañado de Francisco Pastor y tres jóvenes porteadores de la vacuna, a bordo de la fragata Diligencia, pero, aunque a estas alturas de la expedición, los mares les tenían acostumbrados a jugarles malas pasadas, esta travesía se convirtió en la peor de las travesías de las que habían tenido experiencia hasta el momento. Un tifón les sorprendió en el trayecto complicando el viaje hasta tal punto que el propio Balmis lo describió de la siguiente manera "...en pocas horas desmanteló la fragata, con pérdida del palo esana, jarcias, tres anclas, el bote, la lancha y veinte hombres extraviados; no había uno entre nosotros que no esperase por momentos ser sepultado entre las olas del mar... la conservación de la vacuna y el implora la misericordia divina fue todo mi conato, sin que el hallarme solo para toda clase de asistencia para los niños, ni mi falta de fuerzas fuera capaz de postrarme..., llegó por fin el día dieciséis, en que empezó a serenarse el tiempo y en el momento, arrostrando los eminentes riesgos de piratas y ladrones chinos que inundaban esos mares, verifiqué mi desembarco en una pequeña canoa, llevando en mis brazos a los niños, con lo que aseguramos nuestras vidas y la preciosa vacuna". Por fin, a bordo de una pequeña embarcación de pesca china, lograron alcanzar las costas de Macao. 
Desde su llegada a Macao, Balmis, enfermo, empieza a programar su regreso a España, y tras realizar su misión en territorio Chino, decide dejar a su ayudante Antonio Gutiérrez al mando de la expedición por las islas con intención de que éste regrese a México para terminar de conformar la infraestructura de vacunaciones. Él, a su vez, partiría en el primer barco con rumbo a Europa, en el navío portugués, Bon Jesús de Alem, que salía desde Macao con dirección a Lisboa.

Con grandes dificultades económicas para costearse el viaje de regreso, consiguió una financiación de 2.500 pesos para el viaje, obteniendo el préstamo de la Real Compañía Filipina en Cantón, que le serían reembolsados por la Corona española a su llegada a España.

En su viaje de regreso a España, el barco tenía programada una escala técnica en la Isla de Santa Elena, colonia inglesa. Balmis decide transportar consigo una cantidad de vacuna al objeto de implantar la vacunación en la Isla durante el tiempo que el barco permaneciese atracado en ella. Balmis tuvo serias dificultades para convencer al Gobernador de Santa Elena, Robert Patton, por lo que ideó organizar un ciclo de conferencias dirigidas a los médicos locales al objeto de convencerles y que pudieran hacer causa común con él ante el Gobernador, para lo cual, en sus charlas científicas hacía especial hincapié en que la vacunación que pretendía implantar se trataba de un descubrimiento inglés.

Balmis, con su estratégico plan, logró finalmente convencer al Gobernador Patton e implantar la vacunación en la isla. Cuando estaba a punto de abandonarla, durante el transcurso de una comida con el Gobernador Patton la misma víspera de su partida, éste entregó a Balmis un paquete sellado que había recibido de Inglaterra varios años antes. Al abrirlo, Balmis se encontró una dosis de vacuna en linfa e instrucciones para su aplicación, escritas de puño y letra del mismo Edward Jenner; el paquete había permanecido sin abrir durante todo ese tiempo.

Balmis continuó viaje rumbo a Lisboa, donde tras una breve estancia en la ciudad, alquiló un carruaje para regresar a España. Carlos IV le recibió el 7 de septiembre de 1806, felicitándole por su labor al igual que lo hicieron el resto de componentes de la Corte.

\section{SEGUIMIENTO DE LA EXPEDICIÓN DE SALVANY}

El mismo 8 de mayo, fecha en la que Balmis toma la decisión de dividir la expedición, José Salvany y Lleopart, que había sido nombrado Subdirector de la expedición y por tanto, líder de su grupo, parte con dirección a Santa Fe, con la intención de instaurar la vacunación en los territorios de la zona de América Meridional.

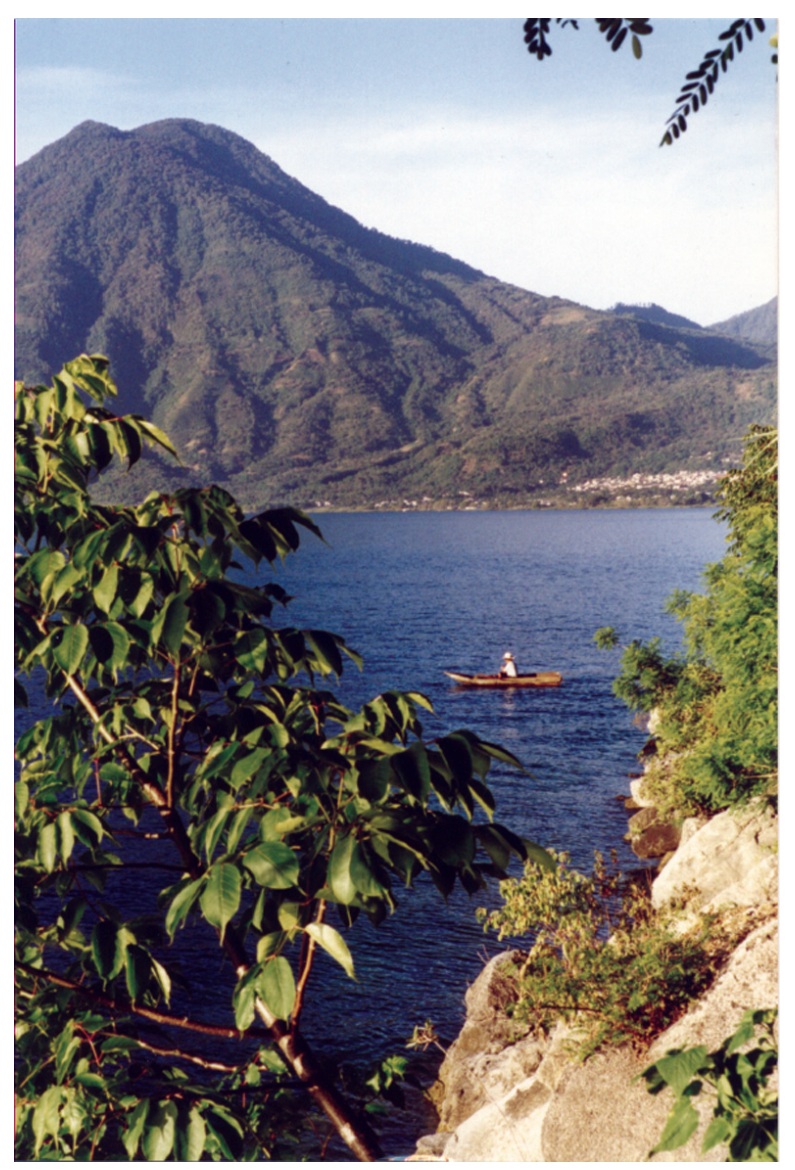

Lago Atitlán. Guatemala. Fotografia: Jorge Veiga.

Para llegar a Santa Fe, tenía que poner rumbo marítimo en dirección al puerto de la Guayra, desde donde se dirigiría hacia Cartagena, perteneciente al Virreinato de Nueva Granada, para alcanzar finalmente Santa Fe. Como el grupo de Balmis había utilizado la corbeta María Pita en su travesía hacia Nueva España, Salvany y su grupo fletan el bergantín San Luis, a bordo del cual se dirigieron rumbo a la Gauyra. La experiencia de navegación a bordo del San Luis fue igual de desastrosa que el resto de navegaciones que habían experimentado hasta el momento por los mares del Caribe, así, al quinto día de navegación, el buque encalló en la boca del Río Magdalena, cerca de la ciudad de la Barranquilla y se vieron obligados a desembarcar precipitadamente en una playa desierta con la ayuda 
de un navío que circulaba por la zona al mando del teniente Vicente Varela. Aunque no hubo víctimas humanas que lamentar, si tuvieron serias pérdidas materiales, sobre todo en lo que se refiere a los instrumentos utilizados para las vacunaciones. El incidente, además supuso que se vieran obligados a continuar el viaje hacia Cartagena atravesando el desierto y las Cienagas de Santa María, lo que además de las incomodidades que suponía, representaba un retraso sobre los planes previstos.

En compensación a este desastre, el grupo de Salvany encontró una excelente acogida al llegar a Cartagena, con un fuerte apoyo por parte las autoridades y apoyo económico del Consulado de Cartagena, el cual, asumió todos los gastos de la operación en su territorio. El grupo de Salvany se vio así compensado, creando su primera Junta Vacunal en Cartagena, desde donde se extendería la vacunación hacia Panamá, Portobello y Buenos Aires, territorios en donde se crearon nuevas Juntas Vacunales.

El 24 de junio, Salvany decide emprender de nuevo el viaje con su equipo en dirección a Santa $\mathrm{Fe}$ de Bogotá, para lo cual, y contando con el apoyo recibido por el Consulado de Cartagena, lograr un grupo de diez niños que les acompañarían en su viaje como portadores de la vacuna. El sistema elegido por Salvany para este trayecto fue la navegación en unas pequeñas embarcaciones llamadas campanes, las cuales utilizarían para navegar a través del río Magallanes. Sabían que este trayecto a través del río, y por experiencia propia en su reciente naufragio, entrañaba un riesgo importante, pero aún así, el riesgo que se corría era menor que realizar el desplazamiento por tierra, atravesando los territorios por la ribera.

La travesía por el río Magallanes en las pequeñas embarcaciones es larga y costosa. Salvany se da cuenta de la enorme extensión del terreno que han de cubrir en su expedición para difundir la vacuna a lo largo del territorio, y para lo cual, solo cuenta con un reducido equipo de cuatro hombres, formado por el facultativo Manuel Julián Grajales, el practicante Rafael Lozano, el enfermero Basilio Bolaños y él mismo. Toma la decisión de que, aunque durante la ruta hacia Santa Fe los cuatro miembros de la expedición permanecerían unidos, a lo largo del trayecto se subdividirían en dos grupos de dos componentes cada uno, al objeto de que cada uno realizase pequeñas incursiones en los territorios que iban atravesando, permitiendo de esta forma abarcar una zona mayor para la expansión de la vacuna.
Aunque pronto, y por razones similares a las que llevaron a Balmis a tomar la decisión de dividir la expedición original en dos grupos, Salvany adopta la misma solución y cada uno de los dos grupos emprende rutas diferentes hasta que se reunieran en la ciudad de Santa Fe. El ayudante Grajales y el enfermero Lozano seguirían su rumbo a través del valle de Chuta, mientras Salvany y el enfermero Bolaños seguirían la ruta de la cordillera. Salvany es una persona de salud débil y con problemas respiratorios, por lo que al pasar Nares y en el ascenso hacia los Andes, Salvany empeora de sus problemas pulmonares y enferma. El Virrey de Santa Fe, enterado de lo ocurrido, y ante la preocupación por el retraso que podía suponer este contratiempo para su llegada a la villa, dispuso una expedición compuesta por un facultativo y 10 niños que salieron a su encuentro, al objeto de dar asistencia a Salvany y poder transportar la vacuna al Virreinato. Finalmente Salvany logró reponerse y aunque quedó ciego del ojo izquierdo, pudo continuar la ruta hacia Santa Fe, donde se encontró con los otros dos expedicionarios. En Santa Fe lograron cumplir su misión con resultados espectaculares, superando las cincuenta mil vacunaciones. El grupo de Salvany instaura en Santa Fe una Junta de Vacunas y además la primera Junta de Sanidad que abarcaba, las funciones propias de la Junta de Vacunas y otras más amplias en el ámbito de la salud pública.

Finalizada la misión en esta ciudad, el grupo expedicionario de Salvany vuelve a dividirse en dos, al objeto de seguir rutas diferentes hasta su próximo encuentro en Popayán. Una vez allí, Salvany recibe la noticia de la propagación de la viruela en la Real Audiencia de Quito, por lo que se dispone a alcanzar esta ciudad a la mayor brevedad posible. De nuevo el grupo, acompañado de los correspondientes niños, se divide. Uno de los grupos, en este caso formado por Salvany y Lozano, se dirigiría directamente a Quito para llegar cuanto antes. El otro grupo, formado por Grajales y Bolaños, también pondría rumbo a Quito, pero pasando por Guayaquil con el fin de vacunar preventivamente a la población de esta ciudad, antes de que pudiera extenderse la epidemia desde Quito y evitar que este importante núcleo comercial, pudiera convertirse en un foco incontrolable para la difusión de la enfermedad.

De nuevo, el grupo expedicionario en el que se encuentra Salvany ha de tomar el camino a través de la cordillera de los Andes, mientras que Grajales y Bolaños pondrían rumbo a Guayaquil vía marítima en el primer navío que se dirigiese hacia territorio panameño. La estrategia tenía sentido práctico sanitario desde el punto de vista preventivo, pero la 
expedición que debía dirigirse hacia Guayaquil fracasó desde el primer momento debido a la presencia de piratas ingleses en la isla de Gorgona y en la punta de la isla de Santa Elena, por lo que los dos grupos volvieron a tomar contacto en Lima para proseguir su viaje juntos hasta Quito.

Una vez más Salvany y su equipo encontraron en Quito una calurosa acogida tanto por la población como por las autoridades locales. En esta ciudad permanecen unos dos meses, porque sufren el robo de 100 pesos fuertes y de parte del equipaje, lo que les supuso un contratiempo que les obligó a retrasar sus planes se salida, y porque Salvany solicita de las autoridades de Quito, la dotación de los comunicados oportunos para llegar a Guayaquil, pues la Real Audiencia de Quito pertenecía al Virreinato de Nueva España y Guayaquil al Virreinato de Perú. Debido al tiempo para recuperar el material robado y a que los tramites administrativos son lentos, la expedición pasa unos dos meses en Quito, retrasando los planes de salida hasta el punto de verse obligados a pasar las Navidades de 1805 en esa ciudad. Tiempo que sirve a Salvany para recuperar su salud. Salvados los inconvenientes, la expedición de Salvany continuó dirección a Cuenca, Loja y a todo el territorio peruano con buena acogida.

Sin embargo, y aunque en general no habían encontrado dificultades en Perú, en la ciudad de Lambayeque las cosas fueron diferentes; la población rehusó la vacuna y Salvany y su equipo fueron acusados de Anticristos. Por el riesgo que para ellos esto suponía, se vieron obligados a abandonar la ciudad precipitadamente, lo que aborta parcialmente la misión de la vacunación en la zona.

Para solventar este inconveniente, y dar continuidad a la misión en la zona, Salvany contacta con un religioso bethelemita, Fray Tomás de las Angustias, presidente del Hospital de Belem de Lambayeque, al que instruye y facilita dosis para que recorra los pueblos de Vicus, Olmos, Mopute, Salas, Jayanca y Pacora, entre otros, logrando con su habilidad y pericia implantar la vacunación en zonas en las que esta práctica se miraba con recelo.

En ese momento reciben noticias de que en la ciudad de Lima se había desencadenado un brote de viruela. Salvany decide poner la expedición de nuevo en marcha con dirección a Lima, pero para ello necesita un número mayor de niños, por lo que decide incorporar a la expedición a Fray Lorenzo Justiniano, para que los niños, en mayor número de lo habitual, pudieran ser convenientemente cuidados. Llegaron a Lima atravesando los Andes con fuertes lluvias y nevadas. En la ciudad se encontraron la desolación de la epidemia y encontraron también una excelente acogida que favoreció la implantación de la vacunación y el control de la epidemia.

La expedición continúa su misión de extender la vacuna por los territorios de América Meridional, en esta ocasión se dirigen hacia Mineral de Chota, que se encontraba amenazada de una epidemia de viruela, con intención de controlar el foco y regresar de nuevo a Lima. En su camino hacia Chepen, los portadores, arrieros y guías les abandonan en una zona inhóspita y totalmente desconocida para ellos, debiendo vagabundear sin orientación durante algún tiempo y con unos niños atemorizados, hasta que fueron recogidos por un hacendado de la zona, Juan de Espinach. Este fue uno de los incidentes que más marcaron a Salvany y a su equipo durante la expedición.

Al regreso de la expedición a Lima, la decepción de Salvany y su equipo es descomunal, se encuentran que la vacuna se comercializa como cualquier bien, no se encontraba controlada por los facultativos, sino por comerciantes que habían encontrado en el líquido una excelente mercancía que les permitía enriquecerse en corto espacio de tiempo. Salvany siente impotencia ante esta situación generalizada, por lo que desmoralizado, abandona las vacunaciones en masa, iniciando la táctica de delegar las operaciones en los médicos locales. Se vincula a la Universidad de San Marcos y a otros foros sociales y políticos influyentes, dedicando gran parte de sus esfuerzos a crear reglamentos que permitan organizar las campañas de vacunación en Perú de una forma coordinada y común desde los poderes públicos.

Una vez solucionados los problemas en Perú y que los canales de vacunación se habían restablecido en Lima, Salvany decide volver a dividir la expedición en dos grupos. La estrategia en este caso era que Grajales se dirijiera a Cuzco y que un mes más tarde emprendiera rumbo marítimo hacia la Capitanía General de Chile desde el puerto de El Callao. Mientras tanto, Salvany partiría en dirección a la ciudad de Arequipa. Sin saberlo, a partir de ese momento los dos grupos tomarían direcciones diferentes y no volverían a encontrarse más.

Este viaje entraña riesgos para la salud de Salvany. Lima, ciudad de la que parten se encuentra a baja altitud, mientras que Arequipa, destino del grupo de Salvany es una ciudad situada en plena sierra de los Andes. Durante el viaje, los problemas res- 
piratorios de Salvany se ven fuertemente agravados, $\mathrm{y}$ aunque el trayecto es relativamente corto, tarda más de dos meses en llegar a Arequipa y cuando lo hace, llega gravemente enfermo, hasta el punto que el certificado médico dice "se confundía con la Apoplejía por la intermitencia del pulso, y por la respiración estertorosa precedida de movimientos convulsivos; y el síncope en su cesación, nos presentaba un espectáculo de horror".

Salvany termina por recuperarse en Arequipa durante las Navidades de 1807. Decide continuar la expedición hacia La Paz, una vez más, atravesando la Cordillera Andina. El trayecto tampoco es excesivamente largo, pero con la delicada situación en la que se encuentra Salvany, el viaje supone un esfuerzo importante y tarda en llegar casi un año y medio, y cuando lo consigue el 1 de abril de 1809, su salud se encuentra ya muy deteriorada. Pero Salvany no se rinde, y su estado de salud no le supone un inconveniente para emprender nuevas misiones. Solicita permiso al presidente de la Real Audiencia de Charcas para adentrarse en las provincias de Mojos y Chiquitos, poblaciones habitadas por indios y misioneros que se veían diezmadas con las frecuentes epidemias de viruela que sufrían. Para Salvany se trataba de una misión de particulares características y en la que había puesto una especial ilusión, pero no logra terminarla. Con su deteriorado estado de salud, José Salvany y Lleopart fallece el 21 de julio de 1810 en Cochabamba, a los 34 años de edad. La última misión iniciada por Salvany en las provincias de Mojos y Chiquitos la finaliza un médico militar 1lamado Santiago Granado, mientras Grajales y Bolaños continúan su expedición por la capitanía General de Chile.

\section{LOS ACONTECIMIENTOS EN ESPAÑA}

Desde 1806, Balmis se encuentra en España, pero en 1808 se había iniciado la invasión por José de Bonaparte. Balmis niega su acatamiento a Bonaparte, por lo que es proscrito y sus pertenencias le son confiscadas. Se ve obligado a marcharse a Sevilla y posteriormente a Cádiz, y en 1809 recibe las primeras noticias de la delicada salud de Salvany.

Pese a la situación que vive Balmis en España y la situación general que se vive en el país, el 30 de noviembre consigue de la Junta Central, un permiso para volver a Nueva España. Balmis reemprende el regreso a América, pero al llegar a México se encuentra con una situación muy distinta a la que había dejado y a la que esperaba. Ante sus ojos, tenía un país que participaba en la invasión francesa y en plena guerra de la independencia, lo que había desorganizado las redes de vacunación que él mismo había creado años atrás. En agosto de 1811 según unas fuentes y en febrero de 1813 según otras, regresa a España, notificando a las Cortes la muerte de Salvany. Francisco Xavier Balmis y Berenguer fallece en Madrid, el 12 de febrero de 1819, a los sesenta y seis años de edad.

En cuanto a la suerte del resto de expedicionarios, no se cuenta con datos de todos ellos. Se sabe que Francisco y Antonio Pastor regresaron a España en 1810, Antonio Gutiérrez vivió en la ciudad de México hasta su muerte y fue considerado como uno de los más prestigiosos médicos de la ciudad, recibiendo una pensión del Gobierno Mexicano como Director Emérito en el Hospital de San Andrés. De la Directora de la Casa de expósitos, Isabel Sendales y Gómez y cuidadora de los niños se sabe poco, posiblemente se quedó a vivir en Puebla de los Ángeles; de ella apenas se tienen referencia, salvo el agradecimiento a su labor que le dedicó el propio Francisco Xavier Balmis y Berenguer: "la miserable Rectora que con el excesivo trabajo y rigor de los diferentes climas que hemos recorrido, perdió enteramente su salud, infatigable noche y dia ha derramado todas las ternuras de la más sensible madre sobre los 26 angelitos que tiene a su cuidado, del mismo modo que lo hizo desde la Coruña y en todos los viajes y los ha asistido enteramente en sus continuas enfermedades...".

Pero no podemos olvidar que detrás de los principales protagonistas que intervienen en esta historia, la Real Expedición Filantrópica de la Vacuna contó con un número difícil de calcular de protagonistas anónimos. Nos referimos a los niños que en todo momento acompañaron a los expedicionarios y que en su anonimato, fueron protagonistas directos del éxito de la misión.

Se sabe que en la corbeta Maria Pita que partió desde la Coruña, salieron 22 niños. Inicialmente se propuso que alguno de los niños procediesen de la Inclusa de Madrid, para lo que se contaba con la conformidad de los médicos, pero la Dirección de la Inclusa, regida por la Junta de Damas del Hospicio y presidida por la Condesa de Montijo, de excelente reputación por su magnífico trabajo, se opuso a esta propuesta al considerar que la expedición no aportaba beneficios de consideración para los niños, en comparación a los riesgos y a los peligros que el viaje podía representar para ellos.

Se planteó la posibilidad de que los niños fuesen seleccionados de la Inclusa de La Coruña, porque la vacuna no se había introducido en esa ciudad; final- 
mente, fueron seleccionados diez niños de la Inclusa de Madrid y doce de la Inclusa de La Coruña, en concreto, de la Casa de Expósitos de Santiago de Compostela.

En lo que respecta a los niños que participaron en la expedición en los territorios de América, la mayoría eran cedidos por las familias a cambio de compensaciones económicas. De algunos de ellos se tienen datos con nombres y apellidos, así como de sus padres, tal es el caso de los 26 niños que participaron en la dura travesía desde Acapulco a Filipinas, y cuya relación se encuentra recogida en el Archivo General de Indias de Sevilla. Otros, y en su mayoría, seguirán siendo protagonistas anónimos de la Historia.

El destino a su regreso a España de los 22 niños que partieron en la expedición desde el puerto de $\mathrm{La}$ Coruña, es incierto y no se sabe con exactitud si el Erario Publico cumplió su parte del trato, promulgada en la Circular para la propagación de la vacuna del 1 de septiembre de 1803, con el compromiso de que "...serán bien tratados, mantenidos y educados, hasta que tengan ocupación o destino con que vivir, conforme a su clase y devueltos a los pueblos de su naturaleza, los que se hubiesen sacado con esa condición". Algunos historiadores manifiestan sus dudas y hacen referencia a la preocupación y tristeza de Balmis por este hecho a su regreso a España.

Sea como fuere, en señal de nuestra admiración, reconocimiento y homenaje a todos los niños que participaron en la expedición, a continuación reproducimos la relación con los nombres de los 22 niños que partieron en la corbeta María Pita desde el puerto de La Coruña, y en la que, pese a nuestro esfuerzo por dotarles de la identidad que les corresponde en virtud a su protagonismo, como podemos observar, el secreto de su anonimato se mantiene presente.

Vicente Ferrer (7 años)
Pascual Aniceto (3 años)
Martín (3 años)
Juan Francisco (9 años)
Tomás Metitón ( 3 años)
Juan Antonio (5 años)
José Jorge Nicolás de los Dolores (3 años)
Antonio Veredia (7 años)
Francisco Antonio (9 años)
Clemente (6 años)
Manuel María (6 años)
José Manuel María (6 años)
Domingo Naya (8 años)
José (3 años)
Vicente María Sale y Bellido (3 años)
Cándido (7 años)
Francisco Florencio (5 años)
Gerónimo María (7 años)
Jacinto (6 años)
Benito Vélez (hijo adoptado de Isabel Sendales y
Gómez).
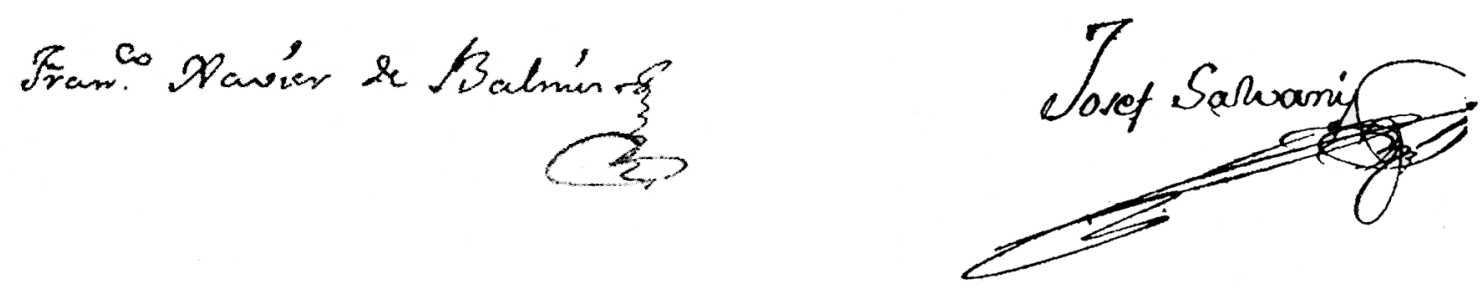


\section{BIBLIOGRAFÍA}

1. Tuells J, Ramírez S.M. Balmis et variola. Valencia. Generalitat de Valencia. 2003.

2. Navarro y García, R. Historia de la Sanidad Marítima en España. 1 ${ }^{\text {a }}$ Edición. Madrid. Instituto de Salud Carlos III. 2001.

3. Balaguer Perigüel, E., Ballester Añon, R. "En el nombre de los Niños. Real Expedición Filantrópica de la Vacuna, 1803-1806" [libro en línea]. Asociación Española de Pediatría, 2003. Colección Monografías de la AEP, $\mathrm{n}^{\mathrm{o}} 2$.

http://www.aeped.es/balmis/libro-balmis.htm [Consulta: 7-12-2007]

4. Ramírez Martín S.M. Capitulo 3. La Real Expedición Filantrópica de la Vacuna (1803 - 1810). Pág. 82-113. Extraído de "Las vacunas doscientos años después de Balmis". Madrid. Instituto de Salud Carlos III. 2004.
5. Núñez Freire B, Núñez Cifuentes U. La expedición de los niños héroes: 16 de julio de 1805 Bicentenario de la llegada de la vacuna de la viruela a la real Audiencia de Quito. CAMBIOS. Órgano Oficial de Difusión Científica del Hospital Carlos Andrade Marín. 2005; 4 (7): 15-24.

6. Gómez-Gonzáles J, Dudvracic Luksic A. La vacuna hace doscientos años. Medivisión. Historia de la Medicina [publicación en línea].

http://www.revistamedica. $8 \mathrm{~m} . \mathrm{com} / \mathrm{misce} 13 . \mathrm{htm}$. [Consulta: 14-12-2007].

7. García de los Ríos J.E., Jiménez Gómez P.A. Bicentenario de la expedición Balmis de la vacuna (1803-06). Actualidad SEM. 2005. 39. [publicación en línea]

http://www.semicro.es/Actualidad/SEM39_8.pdf. [Consulta: 14-12-2007]. 